\title{
The ethnolinguistic vitality of Arabic in the Australian multicultural landscape
}

\author{
Gemma Tarpey-Brown*, Abdel-Hakeem Kasem** \\ *School of Humanities and Social Sciences, Deakin University, Melbourne, Australia; gemmagtb@gmail.com \\ **School of Humanities and Social Sciences, Deakin University, Melbourne, Australia; \\ hakeem.kasem@deakin.edu.au
}

\begin{abstract}
This paper investigates the ethnolinguistic vitality of Arabic in Australian society and the implications such vitality has on claims of a successfully multicultural Australia. Vitality in this regard is defined as 'that which makes a group likely to behave as a distinctive and active collective entity in intergroup situations' (Giles, Bourhis and Taylor 1977, p. 308). To conduct this research, empirical data was collected to understand the way members of the Arabic ethnolinguistic community view their own vitality. Additionally, secondary sources were studied to present an overview of the place Arabic holds within the Australian multicultural landscape. A total number of $53(n=53)$ students across Melbourne were surveyed. The results indicate that when looking at the variable of demography and informal institutional support, Arabic held a high rate of vitality. However, participants believed Arabic had a low vitality in regard to the level of social status and formal institutionalised support.
\end{abstract}

Keywords: ethnolinguistic, ethnolinguistic vitality, Arabic, Arab community, multiculturalism

\section{Introduction}

This research paper investigates the ethnolinguistic vitality of Arabic in Australian society and the implications such vitality has on claims of a successfully multicultural Australia. The research findings will be published in two separate publications. Whilst this paper will focus on analysing and discussing the results of the Subjective Ethnolinguistic Vitality Survey, the second paper will focus on analysing and discussing the relationship between Arabic and Islamophobia and the role of institutional support in language maintenance of Arabic in Australia.

Today, Arabic is the third most spoken language in Australia, following English and Mandarin, meaning it is a central part of communication in the daily lives of over 320,000 Australians (Australian Bureau of Statistics [ABS] 2017). In an international context, Arabic is the official language of 26 sovereign states and is spoken by more than 315 million people worldwide (Simons \& Fennig 2018). It is one of the six official languages of the United Nations. This information allows us to understand the global significance of the language, showing it to be a vital form of communication in the international sectors of economics, politics, security and trade. Yet, the continuing demographic growth of the Arabic ethnolinguistic community in Australia stands in direct contrast with the growing lack of institutional support provided for the language, the normalisation of Islamophobia both in Australia and other Western countries, and the growing rate of racial incivility targeting Arabic speakers. This research project is therefore framed by these conflicting circumstances.

\section{Central question and methodology}

The central research question explored in this paper is "what is the ethnolinguistic vitality of Arabic within Australia, and what implications does this vitality have on claims of a successfully multicultural Australia?". In order to address this question, it was necessary to follow the theoretical framework presented by Bourhis, Giles and Taylor (1981) and Ehala (2010). This framework posits that ethnolinguistic vitality can be assessed by investigating four key variables: the demographics of the community, the level of institutional support given to the community, the social status of the community, and the intergroup distance between the minority ethnolinguistic community, and the majority community ${ }^{11}$. These have been measured by constructing and distributing a Subjective Ethnolinguistic Vitality Questionnaire (SEVQ) to fifty-three young Arabic-speaking Australians in the city of Melbourne, Victoria. The SEVQ is a crucial tool when examining the ethnolinguistic vitality of a language. Bourhis et al. (1981: 147) stressed the importance of the questionnaire "in determining patterns of intergroup behaviours" and for monitoring

\footnotetext{
${ }^{11}$ In this case, Arabic is the minority ethnolinguistic community, and English is the majority ethnolinguistic community.
} 
"the position of minorities as distinctive collective entities in intergroup settings". Given Australia's multicultural history, the issue of rights, respect and representation of minority communities is often at the forefront of social debate.

In addition to ethnolinguistic vitality theory and its methodology, this paper is informed by post-colonial theory, and relies on Ghassan Hage's concept of Australian multiculturalism, which he presents in White Nation (1998), to critically explore the rupture between the presentation of Australia as a multicultural success, and the reality wherein Australians from non-English speaking backgrounds are often made to feel categorically 'un-Australian', and Other (see Ang 2003, Asmar 1992, Hussein \& Poynting 2017).

\section{Literature}

\section{The role of languages in Australia}

Prior to the arrival and implementation of European settler-colonialism, the Australian continent was a space where multilingualism was a necessary part of life. This rich linguistic diversity was eradicated by the British, who instead introduced the norm of monolingualism (Clyne 2011). Where once the continent was home to a rich plethora of indigenous languages, it rapidly became a country that enforced English language proficiency in an attempt to produce a culturally homogenous society (Ang 2003). It is important to situate this research in this history, before noting that multilingualism has once again established itself across the continent, in the Australian linguistic landscape of the $21^{\text {st }}$ century. However today, very few of the languages spoken, taught and maintained in Australia are indigenous to the continent (LoBianco \& Slaughter 2009). Nonetheless, this history of language death does not stop modern Australia from identifying as a country that prides itself on its linguistic diversity and multiculturalism (Piller 2016). Data from the recent 2016 census indicates that $21 \%$ of Australians speak a language other than English at home (ABS 2016).

Arabic has a noted presence in the Australian linguistic landscape, especially in urban centres (Clyne \& Kipp 1999). Piller (2016) focuses on the Australian linguistic landscape and its cultural reality in her work on the intersection of social justice and linguistic diversity, with a case study carried out in the Sydney council area of Auburn. Auburn is one of the most linguistically diverse suburbs in Australia, with $83 \%$ of households speaking a non-English language (ABS 2016) $)^{12}$. In Auburn, Arabic is the primary language spoken at home after English (ABS 2016) and is considered to be a "public but unofficial language" (Piller 2016: 16). The only official language of Auburn Council is English, meaning all official signage, such as street signs, directional signs and signs on public institutions, appear in English. Here, it is argued that in Auburn, there is a clear disjuncture between the monolingual language policy set forth by the council and the prominence of Arabic (and other non-English languages) throughout the community. This is an example of the monolingual mind set that currently exists in Australia, which presents major challenges for language education policy and bilingual development (Clyne 2008, Scarino 2014). The monolingual mind set limits the development of coherent and extensive language policies which should respond to the prominence of community languages in Australian society. This limitation can be seen as producing attitudes that devalue community language bilingualism amongst Australian students and has been read by Zelasko (as cited in LoBianco 2017) to represent the "bilingual double standard". This double standard is found when English speakers who learn foreign languages are celebrated and viewed as intellectually and academically talented. Comparatively, speakers reaching English fluency whilst maintaining their community language are rarely viewed through such a positive lens. Rather, such bilingualism is seen as a necessary form of acculturation, or assimilation, in order to be deemed tolerable (Hage 1998).

\section{Ethnolinguistic vitality}

An ethnolinguistic community is defined by Kramsch (1998) as a community wherein the language, imbued with cultural practices and values, becomes the common identifier of the group. Giles and Johnson (1987) further Kramsch's definition in suggesting that ethnolinguistic communities are formed by drawing on the social psychological processes involved in identity formation. They argue that ethnolinguistic identities are constructed along a complex amalgamation of language, ethnicity and intergroup belonging.

\footnotetext{
${ }^{12}$ For context, $22 \%$ of households speak a non-English language Australia wide (ABS 2016).
} 
Thus, there is a noted connection between an individual's linguistic practices and their cultural identity. This connection is then extended to a wider community, where a person positions herself alongside other members of a speech community who identify similarly. A speech community in this context is akin to an ethnolinguistic community, and such communities often interact and are in contact with each other, especially in the current global environment of hyper-mobility. This hyper-mobility stems from a multitude of factors. However, when discussing the effect of inter-language contact, instances of long term contact are often the focus. Pauwels (2016: 17) lists the main types of mobility that impact the linguistic "constellations" of ethnolinguistic communities as being "migration - voluntary as well as forced, colonisation and invasion". Given the fact that modern Australia is a nation founded by colonisation and relies heavily on immigration, different ethnolinguistic communities are constantly in contact with the national language of English. Therefore, languages in Australia are always experiencing a shift of some kind, often through a stage of bilingualism, and then on to English monolingualism (LoBianco \& Slaughter 2009).

In order to understand the relationship that exists between ethnolinguistic communities in multicultural societies, Giles, Bourhis and Taylor (1977) argue that a language's vitality ought to be studied in order to ascertain how that language is being altered. Vitality in this specific context is defined as "that which makes a group likely to behave as a distinctive and active collective entity in intergroup situations" (Giles et al. 1977: 308). This definition has been extended by Ehala (2010: 204) as that which "manifests itself as group members' readiness to participate in collective action, and this readiness is created by a shared understanding of the world, of the group and of one's relations to both". Giles et al. developed a theoretical framework in 1977, to investigate the role of socio-structural variables in cross cultural communication, language maintenance, language shift, loss and second language learning (Gogonas 2009). This framework presents three main factors that contribute to the ethnolinguistic vitality of a speech community: "status factors (such as economic, political, and linguistic prestige); demographic factors (such as absolute numbers, birth rate, geographical concentration); and institutional support" in the form of recognition of a group and its language in the media, government and educational policy (Giles \& Johnson 1987: 71). However, whilst analysing these factors presents an overall assessment of a group's vitality, Bourhis et al. (1981) also argued that it was important to investigate whether members of the speech community agreed with the so-called objective results ${ }^{13}$. In order to research the perspectives of the speech community the SEVQ was developed (Giles et al. 1977, Bourhis et al. 1981). By collecting data directly from group members, an understanding of how these members minimised or exaggerated the ethnolinguistic vitality of their language could be sought.

Ehala and Yagmur (2011: 101) highlight the pertinence of ethnolinguistic vitality studies in the field of sociolinguistics and social research, due to its ability to monitor the effects of globalisation and increased global mobility on the dynamics of linguistic communities. Highlighting two ways such increased mobility can manifest, the authors first discuss the production of large minority communities in countries that were once culturally homogenous nation-states. The other centres on the potential vulnerability of an ethnolinguistic group, given the "invasion" of dominant languages, cultures and infrastructures. In the case of Australia, both manifestations have occurred ${ }^{14}$, yet the first is most relevant when discussing Arabic. Situating Arabic in its socio-historical context and noting its status as a community language in Australia is a crucial step in researching the language.

\section{Methodology \\ Research design}

In this ethnolinguistic vitality study of Arabic in Australia, a mixed methods approach was used when analysing and discussing the results of the survey, within the theoretical framework provided by Bourhis et al. (1981) and Giles et al. (1977). They posit that ethnolinguistic vitality can be ascertained through empirical research investigating ingroup perceptions of their own community. In order to examine such

\footnotetext{
${ }^{13}$ As ascertained through the collection of documents relating to an ethnolinguistic community's demographic, economic, sociological and historical situation.

${ }^{14}$ The invasion of a dominant language in this context relates to the British colonial destruction and degradation of Indigenous Australian languages.
} 
perceptions, a survey consisting of forty questions was developed that was largely adapted from those presented by both Bourhis et al. (1981) and Ehala (2010). Whilst using the ethnolinguistic vitality framework to carry out the data collection and analysis, the results have been simultaneously framed within the current landscape of Australian multiculturalism, and its Islamophobic undercurrents (see Akbarzadeh 2016, Colic-Peisker et al. 2016). This has been done in an attempt to fully explore the social status prescribed to the Arabic language, and those who speak it, in Australia. Lastly, in presenting the results, the 7-point Likert Scale has been condensed into a 5-point Likert Scale. This means that the two most extreme options, 'strongly agree' and 'strongly disagree', have been merged with 'agree' and disagree' in order to provide better clarity to the frequency graphs and distribution tables.

\section{Instrumentation}

The research project used a forty-question survey adapted from various SEVQs that have been published since 1981. As noted in the literature review, the SEVQ was designed to assess the ethnolinguistic vitality of a speech community by looking at the following three key factors of a specific community:

1. Demography

2. Formal and informal institutional support

3. Social status

After decades of studies that used the Bourhis et al. model, researchers began to note some limitations of the study, primarily regarding its psychometric and quantitative method (see Abrams et al. 2009). Ehala (2010) has since developed another form of the SEVQ, which is based on variables more attuned to the $21^{\text {st }}$ century's globalised, heterogeneous and linguistically diverse societies. Ehala suggests that rather than using the three variables above, SEVQs should instead focus on the following:

1. Perceived strength differential

2. Intergroup discordance

3. Intergroup distance

\section{Utilitarianism of the language}

Given the rapid change of community languages within the linguistic landscape of Australia (ABS 2011, ABS 2016), as well as the decentralisation of institutional, media based, and governmental forms of information, Ehala's SEVQ is a highly relevant tool when trying to answer the primary research question outlined in this article. This is largely because Ehala highlights the importance of intergroup distance. In this instance, "intergroup distance" is defined as the "sum of racial, linguistic, religious and cultural differences between the ingroup" (L1) - which in this case is the Arabic-speaking community - and the dominant cultural group, the monolingual English speakers (L2) (2010: 212). In the article Ehala provides an example to best demonstrate a situation where a high level of intergroup distance would exist. The example he offers is that of a minority Muslim community residing in a predominantly white/Christian European city. He argues that this situation, given the two groups distinct religious identities, will have a substantially large intergroup distance. According to Ehala's SEVQ, if the intergroup distance is perceived to be large, then the likelihood of the minority ethnolinguistic community losing its distinct cultural and linguistic identity and undergoing language shift at an advanced rate are low. The Arabic speaking community in Australia has often been viewed as the enemy within (Hage 2002), or the 'pre-eminent folk devil' (Poynting et al. 2004: 3), experiencing targeted, racialized violence (Human Rights and Equal Opportunity Commission 2003, Dunn 2004, Itaoui \& Dunn 2017). Given these factors, it may be the case that the community will perceive itself to be quite distant from that of the linguistically dominant Englishspeaking community.

\section{The subjective ethnolinguistic vitality questionnaire}

The forty questions in the survey were broken up into different categories, depending on their structure. The first 20 questions were mostly comparative, where the participants were asked the same questions about both Arabic and English and had to rate their response on a seven-point Likert scale. The second section of the survey focused on language use, with the aim of producing a comprehensive understanding 
of the main language domains (Fishman 1964) Arabic is spoken in, from the family domain, through to the friendship domain and the educational domain. Following on from this, some additional questions were included wherein participants were asked about their experiences of racism, and whether there was a higher rate of racial abuse directed towards them whilst they spoke Arabic. Furthermore, participants were asked to express their own opinions regarding the effect Islamophobia is having on the way in which both native and non-native language learners engage with Arabic. The final three questions on the survey asked participants to note their gender, age and the languages they spoke at home. These questions were asked for demographic purposes, as well as to collect further data on language maintenance efforts within the Arabic ethnolinguistic community.

\section{Research locations}

The research was carried out at three Victorian government secondary schools in the Local Government Areas (LGAs) of Hume and Moreland. Both suburbs are located in the north of Melbourne and were selected based on demographic factors relating to the linguistic composition of the LGAs.

\section{Research sample}

Participants were sought from local government secondary schools across Hume and Moreland. The pre-requisites for participants were that they were from Arabic-speaking backgrounds, identified as members of the Arabic community and were at least 18 years old. The age of participants ranged from 1823 , with most being 18 years old $(n=34)$. This means that this ethnolinguistic vitality study is informed by the opinions of Arabic-speaking Australian youth, from both first and second-generation backgrounds. Given that a high percentage of the Arabic speaking community in the Hume council area were born in Iraq, some of the Year 12 students who participated had experienced an interrupted education. Gender parity between participants was also sought, however most participants were female $(n=37)$. At the end of the data collection process, the total number of surveys collected and analysed was $53(n=53)$.

\section{Findings and discussion}

The results of the SEVQ are presented in tables and frequency distribution graphs. The results have then been evaluated and critically analysed. The questionnaire collected key information on factors pertaining to the demographics and social status of the Arabic-speaking community, as well as the level of institutional support (both formal and informal) received, and the perceived intergroup distance between the Arabic ethnolinguistic community and the majority English speaking community. These four factors, when combined, "interact to provide the context for understanding the vitality" (Giles et al. 1977: 309) of Arabic in the Australian multicultural landscape.

\section{Subjective ethnolinguistic vitality results}

The results of the SEVQ are divided into the four variables that contribute to ethnolinguistic vitality: social status (Figures 1, 2, 3 and 4), demographics (Figures 5 and 6), the level of formal and informal institutional support received by the Arabic ethnolinguistic community (Figure 7) and the perceived intergroup distance between itself and the dominant English-speaking community (Figures 8 and 9).

\section{Social status}

The questions examining perceptions of the social status of Arabic were mostly comparative, whereby the results indicated that the English-speaking and Anglo-Australian community were always perceived to have a higher vitality rate than the Arabic ethnolinguistic community.

Figure 1 below shows that 51\% of participants believed Arabic culture and tradition were "somewhat highly regarded" in Australia and $19 \%$ believed it be "highly regarded". Comparatively, $40 \%$ believed AngloAustralian culture and tradition to be "highly regarded", and 38\% responded "somewhat highly regarded". Such figures demonstrate that participants believed Anglo-Australian culture and tradition to be only slightly more regarded than the cultures and traditions associated with their own Arab heritage. 
Figure 1: Perception of Arabic and Anglo-Australian culture and tradition in Australia.

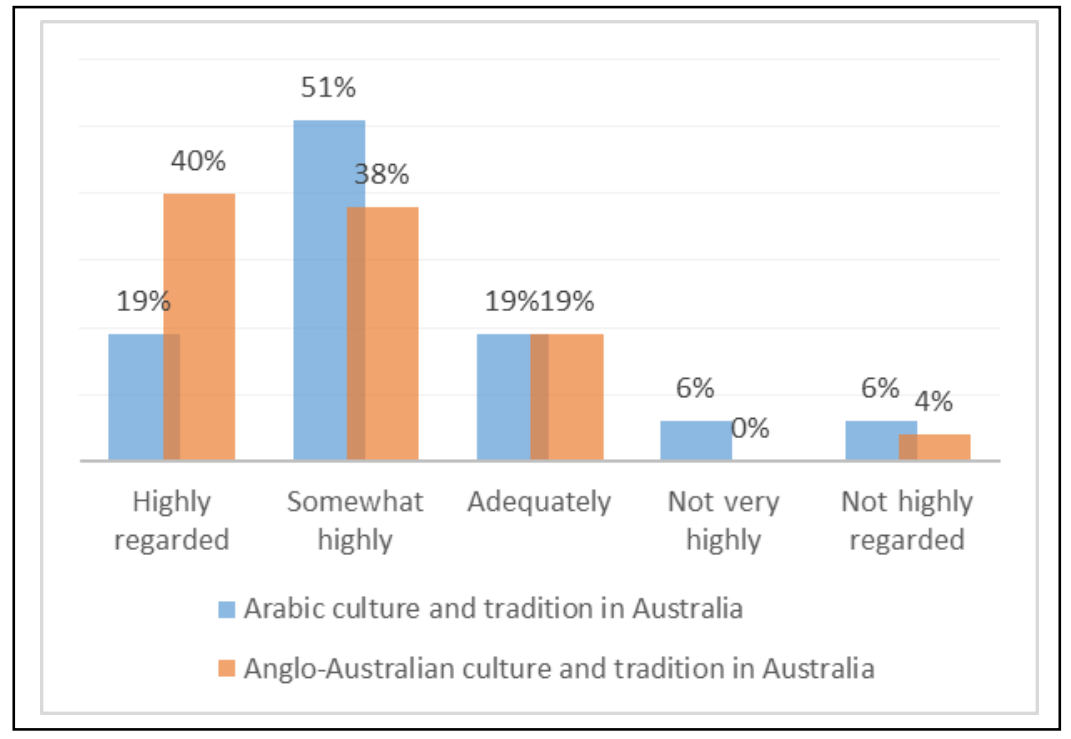

For many Arabic-speaking Australians, the Arabic language is key to their culture and their roots (Clyne \& Kipp 1999: 156). In Figure 2 below, responses to the question "how highly regarded is the Arabic language in Australia?" showed that $25 \%$ of participants believed it was highly regarded. Yet when asked how highly regarded Arabic was internationally, 38\% responded saying it was "highly regarded". A similar trend is seen regarding English, in that $78 \%$ said the language was highly regarded in Australia, yet this increased to $89 \%$ in the international context. This result suggests participants were aware of the dominant role English plays in international institutions and businesses and how it acts as a global lingua-franca (De Swaan 2013).

Turning to the gap found between the perception of how Arabic is regarded here in Australia, compared with internationally, this indicates that the Arabic-speaking Australians surveyed believed Australian society views Arabic with less regard than the international community. Here is the first indication that the Arabic ethnolinguistic community perceive the anti-Arab, and more broadly Islamophobic, attitudes currently permeating Australian culture are affecting the social status of their language in Australian society.

Figure 2: Perceptions of Arabic and English language in Australia.

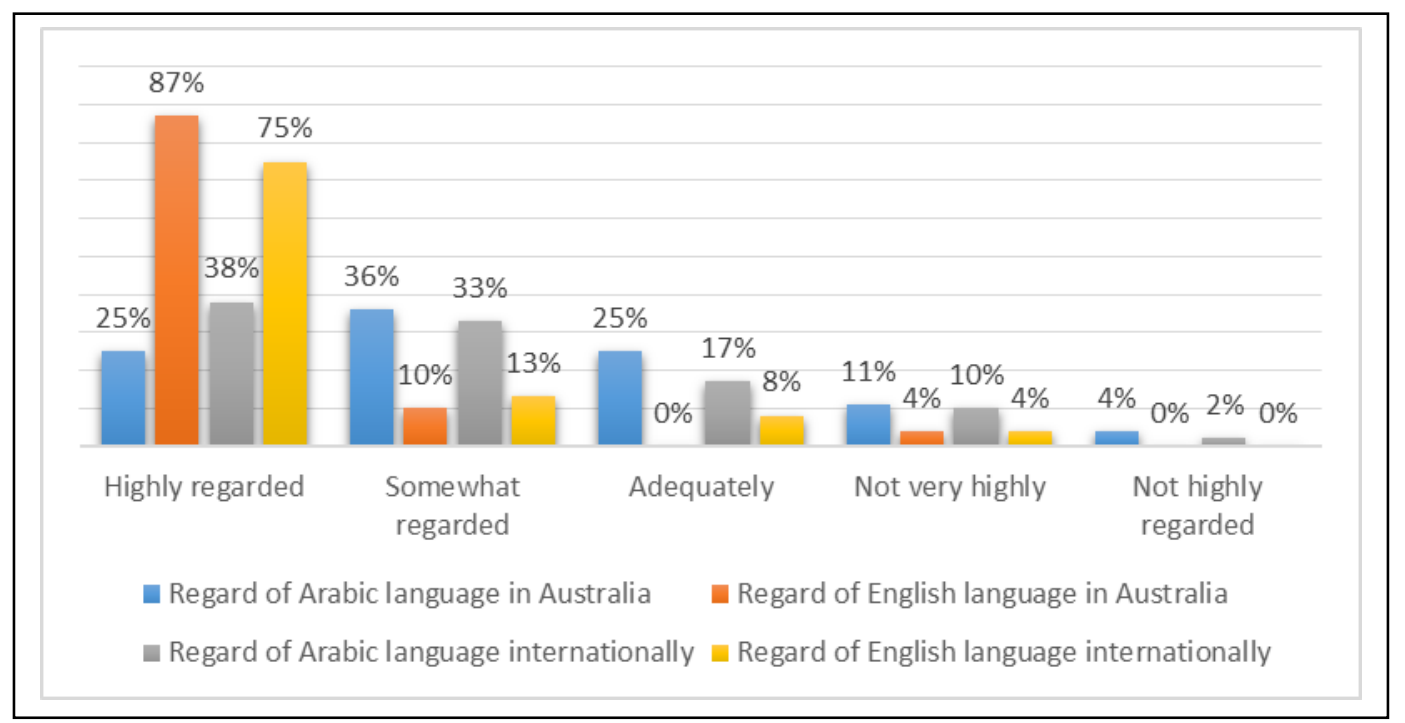

Further exploring perceptions of the social status of Arabic, Figure 3 below demonstrates the marked difference in respect granted to speakers of Arabic and speakers of English in Australia. Notably, no 
participants disagreed with the statement that English speakers were highly respected, whilst $21 \%$ of participants either somewhat or fully disagreed with the statement that Arabic-speakers were highly respected in Australian society. The distinction between respect granted for English speakers in Australian society, compared to those who speak Arabic brings to the fore Australia's monolingual mind set. Alongside this we see undercurrents of assimilationist ideals. Whilst the White Australia Policy has been dismantled, and the dictation test removed, the primacy granted to Australia's Anglo-Celtic heritage lingers on (Hage 1998: 82). This is evidenced by the fact that the Australians from Arabic speaking backgrounds who were surveyed feel their heritage, expressed through language, is not granted anywhere near the same level of respect as the English language in Australian society.

Figure 3: Perception of English and Arabic speakers in Australian society.

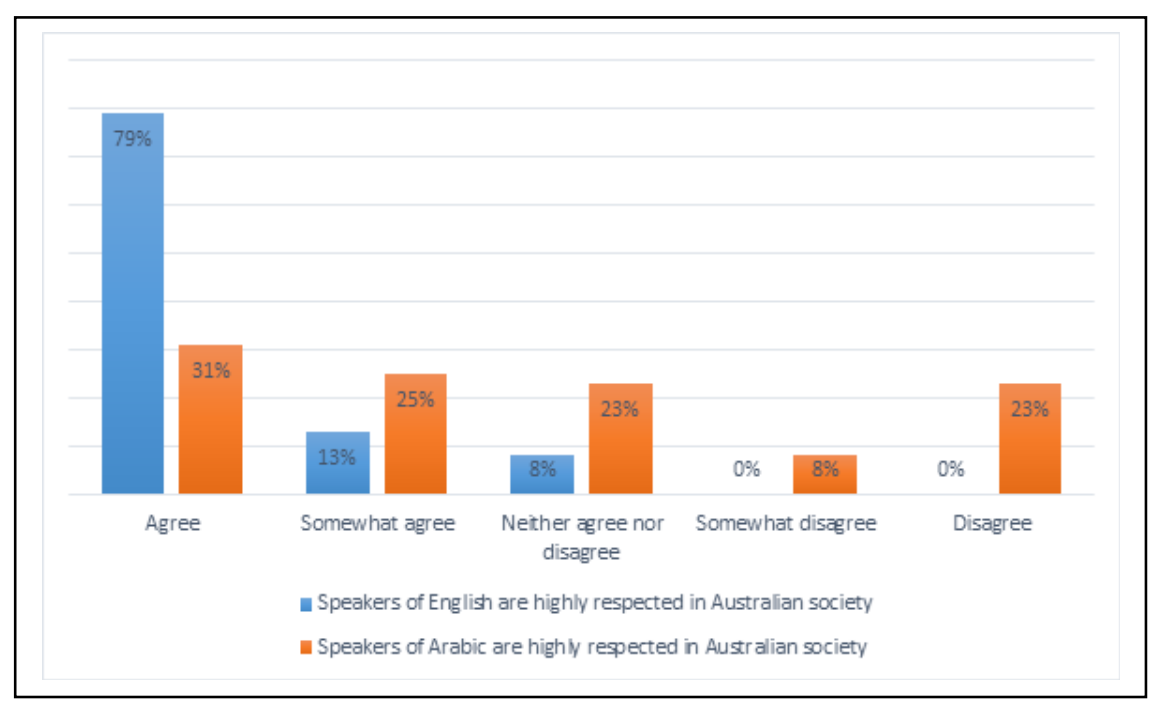

Figure 4: Negative representations of Arabic speakers in the media change attitudes toward Arabic.

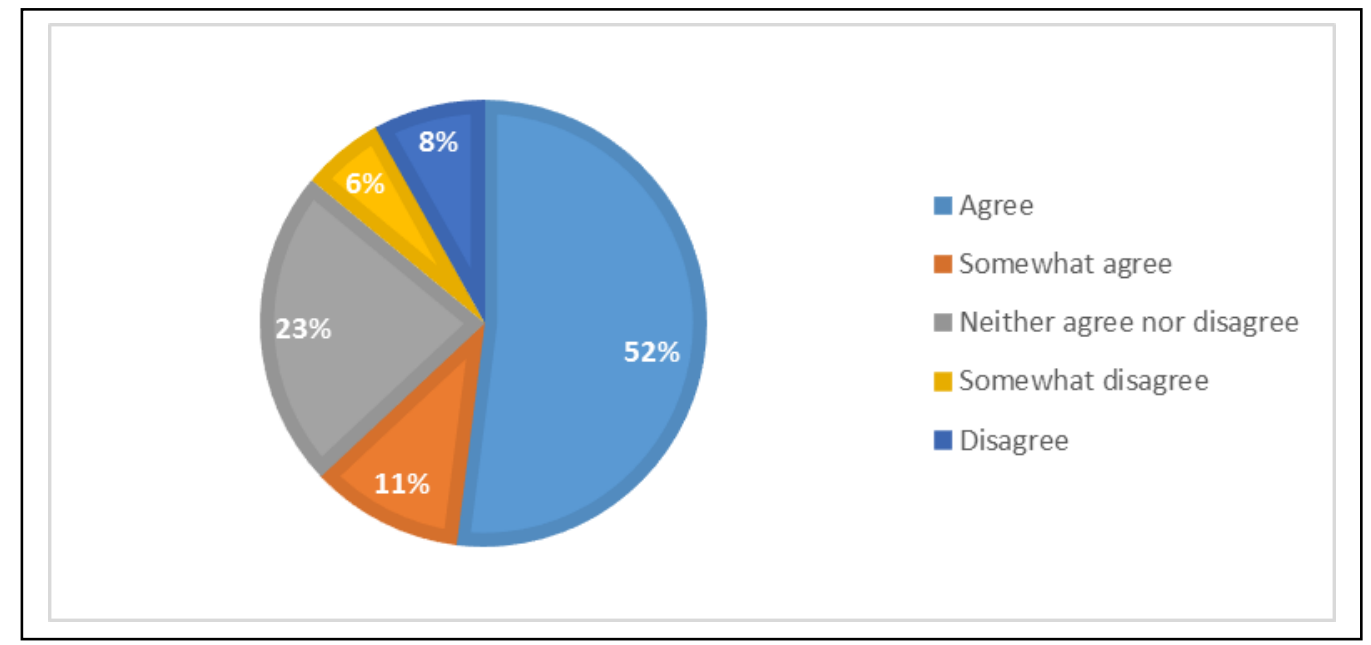

The notion of respect is an important one when looking at the social status of Arabic, for as Landry and Allard (1994: 5) argue, the status variable pertains to the prestige of the linguistic group in the society at large. Smolicz (1987) is more specific, in that he states outsider evaluation of the minority language wherein the speakers of the majority language regard it respectfully is crucial in maintaining a high language status.

Figure 4 above indicates that $52 \%$ of participants believed negative representations of Arabic speakers in the media change attitudes toward the language. Such beliefs are supported by the fact that in 2017, a study into five Australian newspapers owned by News Ltd. revealed that in the space of twelve months, 
2,891 negative articles were written about Muslims and Islam ${ }^{15}$ (OnePath Network 2018). Of these 2,891 articles, 152 of them were front page news. For the Arabic-speaking Australians surveyed, it appears notions of respect and prestige aren't part of the equation when speakers of Arabic are presented in the Australian media, a social institution where "Muslims have been characterized as non-members of the Australian community - relegating them to the space of the 'other', alien, foreign and incompatible with Australian cultural values" (Aly 2007: 32). Whilst this is not a uniquely Australian phenomenon (see Ahmed \& Matthes 2016, Osuri \& Banerjee 2004, Said 1997), it is an ever-present factor within our society, and as the majority of the Arab-Australians who participated believed, it is continuing to negatively affect attitudes towards the Arabic language.

\section{Demographics}

The demographic variables in this study related to perceptions of the Arabic ethnolinguistic community, including their distribution throughout Australian cities, their sheer size (Giles et al. 1977: 309) and their proportional representation (Shaaban \& Ghaith 2002) in the linguistic landscape of Australia. Participants' awareness of their community's size and growth is shown below in figure 5 , where $42 \%$ agreed that the Arabic-speaking population was increasing in Australia. Conversely, 19\% disagreed, believing that their community was not increasing. These results indicate that the participants had a sound awareness of their community's size and growth patterns. For, as discussed earlier, the Arabic speaking population is indeed continuing to grow across Australia ${ }^{16}$. It is also a relatively young community, with census data revealing that in New South Wales, 69\% of Arabic speakers are under the age of 44 (ABS 2016). This suggests that in the next few decades, the population will remain relatively constant, as emigration from Australia is unlikely. The fact that $42 \%$ of participants believed their community to be increasing suggests that the community is welcoming new members and is acting as a cohesive unit. Whilst such results suggest the community has a good rate of vitality, it may alternatively be the consequence of xenophobic media reporting. This could stem from the fact that often, the Arabic ethnolinguistic community, and by extension the Muslim community, is reported to be "taking over" Australian suburbs, transforming them into a "monolingual and monocultural ghetto" (Tim Blair as cited in Abdel-Fatteh 2017: 1). By inferring Muslims/Arabs are taking over, the size of the community is exaggerated.

Figure 5: Increase of the Arabic speaking population across Australia.

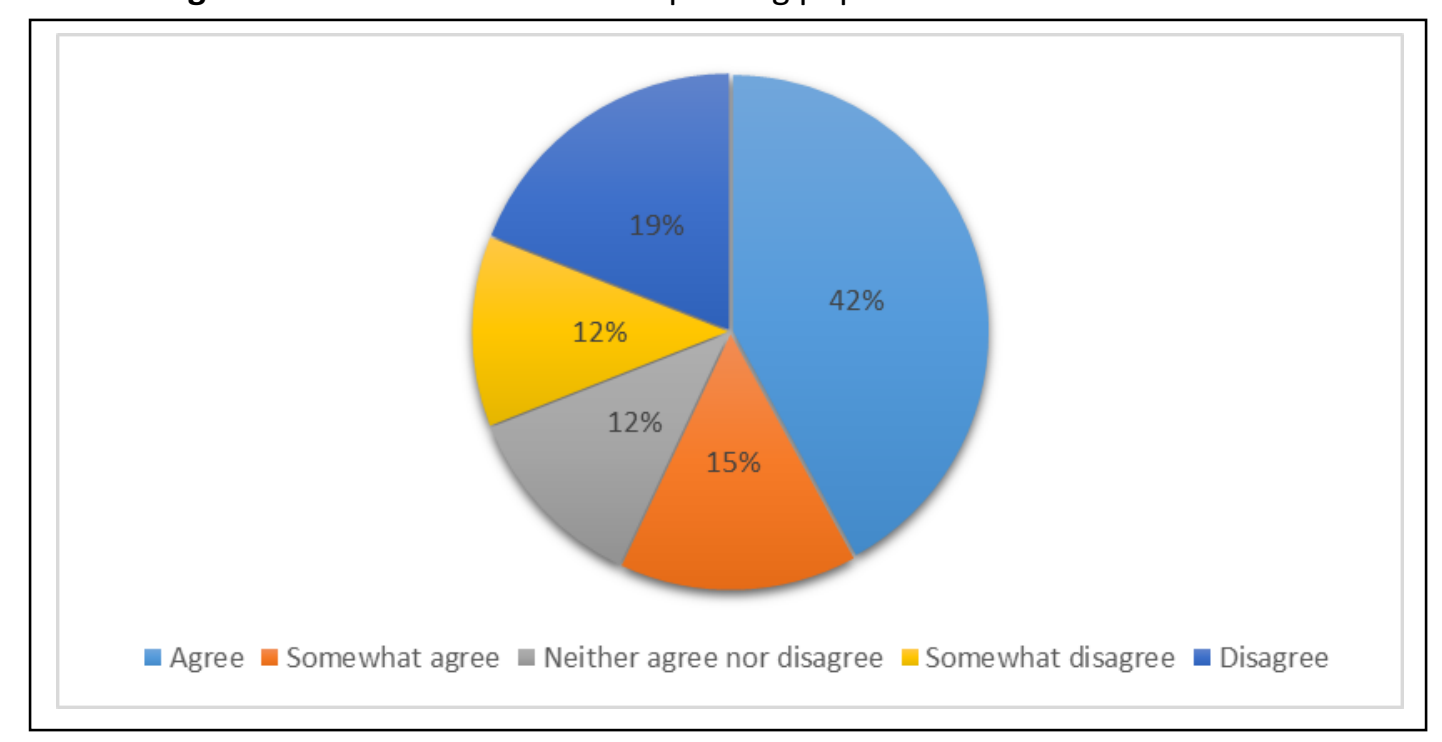

\footnotetext{
15 The study denoted an article as negative if it referred to Islam or Muslims alongside words such as radical, violence, terrorist and extremism

${ }^{16}$ Between 2011-2016 in the state of Victoria alone, the population grew by over 11,000 people (ABS 2011, ABS 2016)
} 
Figure 6 below outlines the responses to a comparative question which asked participants how strong and active the Arabic ethnolinguistic community is in Australia today, and how strong and active it will be in twenty years. It also asked the same question regarding the English-speaking community. By asking participants to assess how active their community is, we are given an insight into the vitality of the community as seen by its members (Noels, Kil \& Fang 2014). Participants believed that today, the Arabic ethnolinguistic community is seen to be "somewhat strong and active" (37\% of participants). However, the majority of participants (51\%) believed that in twenty years the community will be "very strong and active". When looking at the response to the questions that dealt with the English-speaking community, a direct reversal of opinion is evident. $75 \%$ of participants believed that today, English is a "very strong and active" language in Australia. Yet, when asked how strong and active it will be in twenty years, this percentage dropped. The participants' perceptions clearly suggest that they believed the dominance of English in Australia will decline over the next two decades, whilst the Arabic ethnolinguistic community will become more active within the broader society and therefore increase in vitality. Such beliefs could instigate and further encourage language maintenance efforts and ensure the ethnolinguistic vitality of the community does not experience a decline. Additionally, it indicates the belief that English language will no longer remain as dominant as it is today across Australia, possibly suggesting that a more pluralistic and multilingual Australia is inevitable, regardless of how entrenched the monolingual mindset may be.

Figure 6: Community strength and activity.

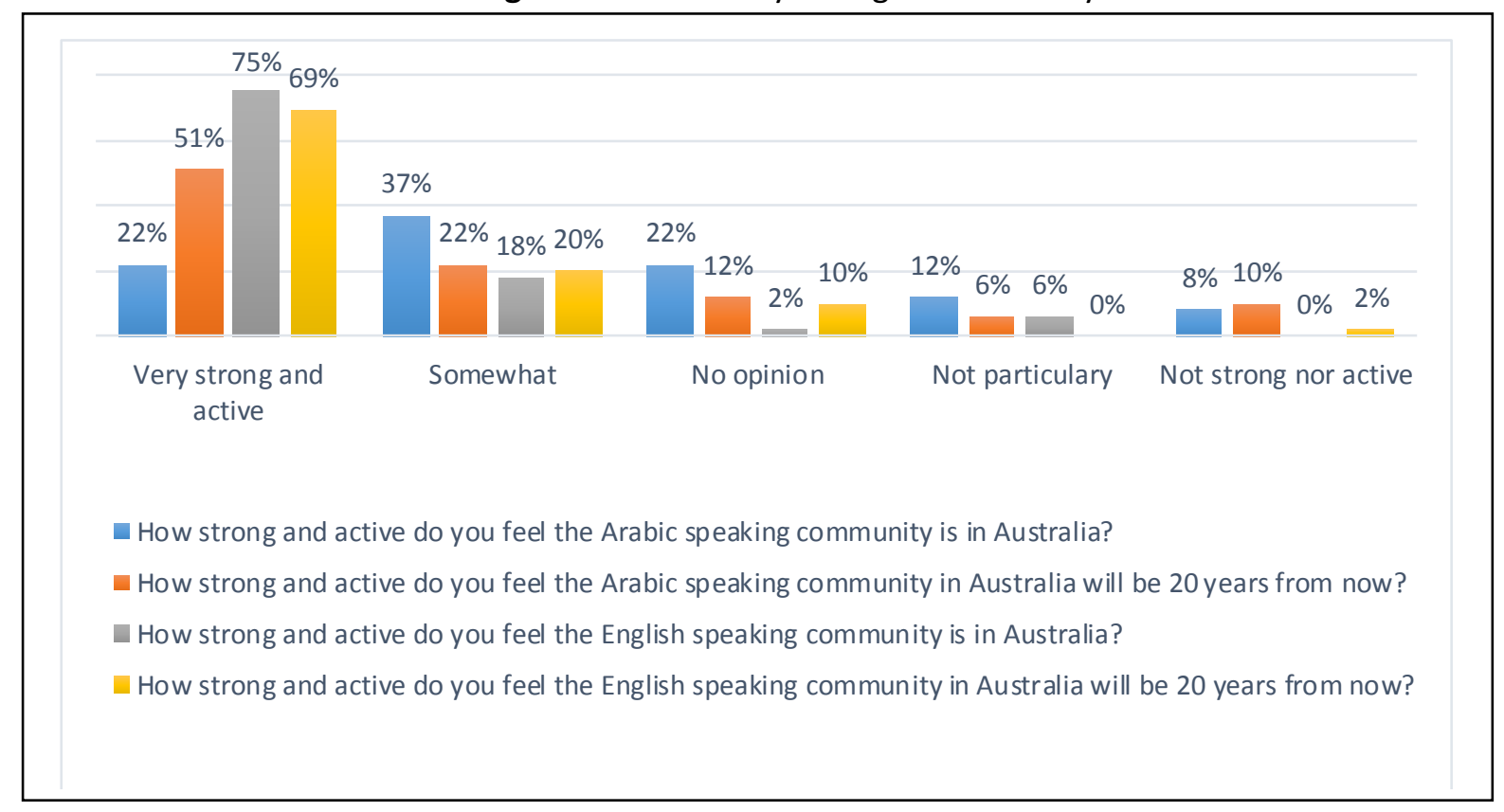

\section{Formal and informal institutional support}

The three questions that examined perceptions of institutional support focused on cultural events, education, and media. According to Yagmur (2011), these factors are the hardest to measure through the SEVQ. This is due to the focus the survey places on formal institutional support rather than investigating the community's own institutional structures that promote internal solidarity.

The questions in this section of the survey followed the same comparative structure, whereby participants were asked about the support given to both Arabic/Arab and English/Anglo-Celtic resources (Figure 7 below). On all three factors English was always perceived to be substantially more supported than Arabic. Whilst not surprising considering English is the national language, it does conflict with Australia's multilingual past, present and future (Clyne 2005), and clashes with the presentation of the Australian nation as a 'truly pluralist' cultural egalitarianism (Hage 1998: 83). As demonstrated by the 
participants' responses, the tensions between 'being' Australian and speaking languages other than English, remains prevalent throughout the culture and society today.

Figure 7: Representation of Arabic and English language in culture, media and education.

\begin{tabular}{|c|c|c|c|c|c|c|c|}
\hline Questions & $\begin{array}{l}\text { Total } \\
\text { (N) }\end{array}$ & $\begin{array}{c}\text { Very Well } \\
\text { Represented } \\
(\%)\end{array}$ & $\begin{array}{c}\text { Somewhat } \\
\text { Represented } \\
(\%)\end{array}$ & $\begin{array}{c}\text { Adequately } \\
\text { Represented } \\
\text { (\%) }\end{array}$ & $\begin{array}{c}\text { Not Very } \\
\text { Represented } \\
(\%)\end{array}$ & $\begin{array}{c}\text { Not } \\
\text { Represented } \\
(\%)\end{array}$ & $\begin{array}{l}\text { Most } \\
\text { Frequent } \\
\text { Response }\end{array}$ \\
\hline $\begin{array}{l}\text { How well is the Arabic speaking } \\
\text { community represented in certain } \\
\text { aspects of cultural life (such as } \\
\text { festivals, concerts, art exhibitions, } \\
\text { conferences etc.) in Australia } \\
\text { today? }\end{array}$ & 53 & $23 \%$ & $36 \%$ & $30 \%$ & $9 \%$ & $2 \%$ & $\begin{array}{c}\text { Somewhat } \\
\text { Represente } \\
\text { d (36\%) }\end{array}$ \\
\hline $\begin{array}{l}\text { How well is the Anglo-English } \\
\text { speaking community represented } \\
\text { in certain aspects of cultural life } \\
\text { (such as festivals, concerts, art } \\
\text { exhibitions, conferences etc.) in } \\
\text { Australia today? }\end{array}$ & 53 & $49 \%$ & $30 \%$ & $17 \%$ & $2 \%$ & $2 \%$ & $\begin{array}{l}\text { Very Well } \\
\text { Represente } \\
\text { d (49\%) }\end{array}$ \\
\hline $\begin{array}{c}\text { How well represented is the } \\
\text { Arabic language in the mass } \\
\text { media? }\end{array}$ & 53 & $15 \%$ & $26 \%$ & $26 \%$ & $21 \%$ & $11 \%$ & $\begin{array}{l}\text { Somewhat } \\
\text { Represente } \\
\text { d (26\%) }\end{array}$ \\
\hline $\begin{array}{l}\text { How well represented is the } \\
\text { English language in the mass } \\
\text { media? }\end{array}$ & 53 & $79 \%$ & $13 \%$ & $4 \%$ & $4 \%$ & $0 \%$ & $\begin{array}{l}\text { Very Well } \\
\text { Represente } \\
\text { d (79\%) }\end{array}$ \\
\hline $\begin{array}{c}\text { How well represented is the } \\
\text { Arabic language in education in } \\
\text { Victoria? }\end{array}$ & 53 & $25 \%$ & $19 \%$ & $25 \%$ & $19 \%$ & $13 \%$ & $\begin{array}{l}\text { Very Well } \\
\text { Represente } \\
\text { d (25\%) }\end{array}$ \\
\hline $\begin{array}{l}\text { How well represented is the } \\
\text { English language in education in } \\
\text { Victoria? }\end{array}$ & 53 & $87 \%$ & $8 \%$ & $4 \%$ & $2 \%$ & $0 \%$ & $\begin{array}{l}\text { Very Well } \\
\text { Represente } \\
\text { d (87\%) }\end{array}$ \\
\hline
\end{tabular}

In Figure 7 above, we are able to see that of all three factors, educational support for Arabic was seen to be the most well represented. One quarter of participants believed that the Arabic language was "very well represented" in the education sector in Victoria. Comparatively, $87 \%$ stated that English is "very well represented" in education across the state of Victoria. The fact that $32 \%$ of participants believed Arabic is "not very well" or "not represented" is supported by the lived experience of the participants, considering that 42 of the 53 participants had to spend their Saturday mornings at a local government school in order to learn the language, as it was not offered as part of their schools' curriculum (DET 2017). It is important to frame these results alongside the issues raised by LoBianco and Slaughter 
$(2009)^{17}$. They argue that Australia is experiencing a deep and persistent malaise in language education, whereby the linguistic diversity within society is increasing, yet educational policy surrounding additional language learning is far more restrictive than it was in the late 1980s-1990s (LoBianco 2010). When looking at the educational support provided to Arabic specifically, a clear trend emerges. As the population of Arabic speaking Australians has increased, the level of educational support granted to the language has decreased. A decade ago, in 2008, Arabic was taught in eleven public schools ${ }^{18}$ across the state of Victoria (Department of Education and Training [DET] 2010). Today, this number sits at five ${ }^{19}$ (DET 2017). Regarding enrolments, there was a surge between 2007 and 2010. From 2011 overall enrolment numbers once again began to decrease. The steep decrease in educational language support given to the Arabic language limits the vitality of the ethnolinguistic community, in that the language is being largely ignored by policy makers, and the multilingual skills of Arabic speaking Australians are not being harnessed, remaining an untapped national resource (LoBianco \& Slaughter 2009).

Turning to institutional support from the mass-media, $21 \%$ of participants believed that Arabic was "not very well represented" in Australian media, whilst one participant wrote that Arabic was represented "badly" in the media ${ }^{20} .26 \%$ of participants believed it was "somewhat represented". On the other hand, English was seen to be "very well represented" within the Australian media (79\% of participants). Yagmur's argument regarding the difficulty of the SEVQ to fully capture the level of informal institutional support is highly relevant here, as the Arabic ethnolinguistic community produces multiple Arabic language newspapers, holds many religious and social events where Arabic is the primary language spoken (Clyne \& Kipp 1999) and is active across multilingual community radio stations (Hess \& Waller 2015).

Regarding the Arabic community being represented in cultural events, $23 \%$ thought that it was "very well represented". Comparatively, $49 \%$ of participants believed the Anglo-English speaking community was "very well represented" across certain aspects of cultural life in Australia. These responses exacerbate the idea of Australia as a nation that heralds its Anglo-Celtic history and heritage, ignoring both its linguistically diverse citizenry, and its true history as "a white settler society founded on the expropriation of Aboriginal land and the denial of the very humanity of Indigenous people" (Hussein \& Poynting 2017: 341).

\section{Intergroup distance}

The intergroup distance variable was introduced to the theory of ethnolinguistic vitality by Ehala (2010), who argues that this variable is determined by both discursive and symbolic factors. Clyne (2005) also notes the importance of distinct cultures when looking at languages in migrant communities. He posits that the more cultural distance an ethnolinguistic community is from the mainstream AngloAustralian identity, the more the language will continue to be spoken, and maintained. The results presented below in Figure 8 illustrate Clyne's argument. 38\% of participants agreed Arabic speakers held a different world view to English speakers. Here, whilst noting that there is a marked difference between the world view of Arabic and English speakers, participants may be showing their adherence to the renowned Sapir-Whorf hypothesis ${ }^{21}$. On a similar note, $47 \%$ of participants believed that the language they spoke highly effected what others thought about them.

Nonetheless, how does the idea of a language shaping and defining a person's reality reflect on the ethnolinguistic vitality of Arabic? For the most part, it establishes that the Arab-Australians surveyed believed their world view to be different from that of Anglo-Australians. From this, it is inferred that there is a prominent intergroup distance between the two ethnolinguistic groups. This distance suggests that members of the Arabic ethnolinguistic community have a distinct identity. Such distinctive identity

\footnotetext{
${ }^{17}$ The work of LoBianco and Slaughter (2009) is discussed in the literature review.

${ }^{18}$ Six of which were primary schools, five were secondary schools.

19 Three of these schools are secondary, and two are primary.

20 The question was misinterpreted by the participant. However, their response is relevant given the results shown in Figure 5 .

${ }^{21}$ Sapir and Whorf put forth that 'the structure of anyone's native language strongly influences or fully determines the world-view he [sic] will acquire as he [sic] learns the language' (Brown as cited in Kay and Wempton 1984: 66).
} 
makes it difficult to shift one's group membership, and therefore also difficult to lower the group's vitality (Ehala 2010).

Figure 8: Perceptions on Arabic and English language speakers.

\begin{tabular}{|c|c|c|c|c|c|c|c|}
\hline Questions & Total (N) & Agree (\%) & $\begin{array}{c}\text { Somewhat } \\
\text { Agree (\%) }\end{array}$ & $\begin{array}{c}\text { Neither Agree } \\
\text { nor Disagree } \\
(\%) \\
\end{array}$ & $\begin{array}{l}\text { Somewhat } \\
\text { Disagree (\%) }\end{array}$ & Disagree (\%) & $\begin{array}{l}\text { Most Frequent } \\
\text { Response }\end{array}$ \\
\hline $\begin{array}{l}\text { The world view of Arabic } \\
\text { speakers is different to the } \\
\text { world view of Anglo-English } \\
\text { speakers }\end{array}$ & 52 & $38 \%$ & $10 \%$ & $23 \%$ & $23 \%$ & $6 \%$ & Agree (38\%) \\
\hline $\begin{array}{l}\text { Arabic speakers can be } \\
\text { identified by their visual } \\
\text { appearance. }\end{array}$ & 51 & $18 \%$ & $29 \%$ & $27 \%$ & $14 \%$ & $12 \%$ & $\begin{array}{l}\text { Somewhat } \\
\text { Agree (29\%) }\end{array}$ \\
\hline $\begin{array}{l}\text { All Arabic speakers are } \\
\text { Muslim }\end{array}$ & 52 & $6 \%$ & $0 \%$ & $6 \%$ & $6 \%$ & $83 \%$ & Disagree (83\%) \\
\hline $\begin{array}{l}\text { All monolingual English } \\
\text { speakers are Christian }\end{array}$ & 52 & $17 \%$ & $15 \%$ & $13 \%$ & $2 \%$ & $52 \%$ & Disagree (52\%) \\
\hline $\begin{array}{l}\text { The language you speak } \\
\text { effects what people think } \\
\text { about you }\end{array}$ & 49 & $47 \%$ & $16 \%$ & $24 \%$ & $6 \%$ & $6 \%$ & Agree (47\%) \\
\hline
\end{tabular}

Regarding religion, and the role of language in shaping ethnic identity, $29 \%$ of participants "somewhat agreed" that Arabic speakers could be identified by their visual appearance. One participant added that this was true "mostly for women". The assumption that the participant was referring to the hijab plays on the slippage between Arab and Muslim identity. However, the conflation between Arabic speaker and Muslim was negated by the majority of participants, with $83 \%$ disagreeing to the statement "all Arabic speakers are Muslim". Given that 17 of the participants spoke Chaldean and Assyrian alongside Arabic, there was obvious acknowledgement of the ethnic and religious diversity within the Arabic ethnolinguistic community. Most participants (52\%) also disagreed with the statement "all English speakers are Christian". This shows that whilst there is a distinct level of intergroup distant regarding heritage culture, the participants are well aware of the equally complex and heterogeneous identities of monolingual English-speaking Australians. 
Figure 9: Sense of belonging to the Arabic and English ethnolinguistic communities.

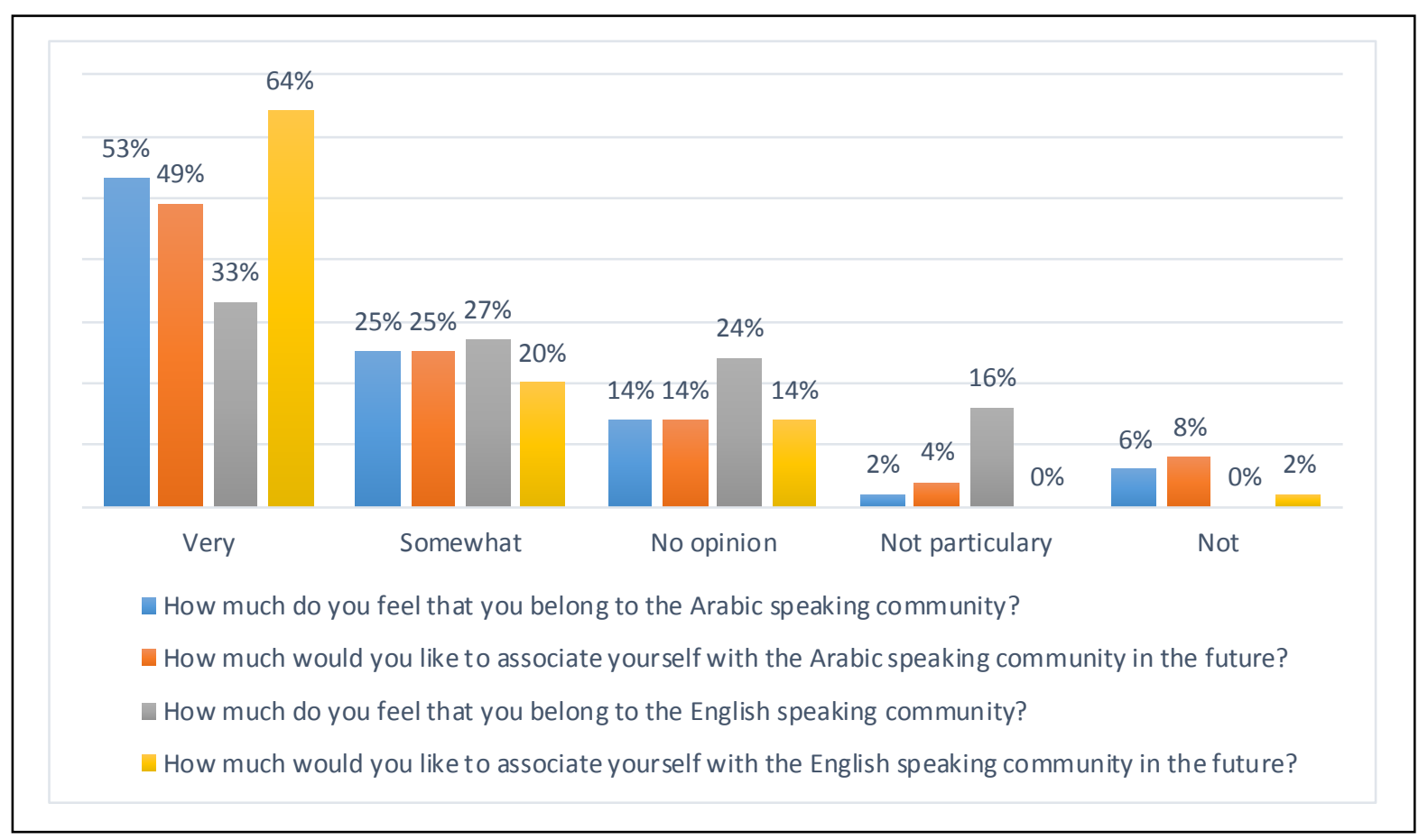

Figure 9 above demonstrates participants' sense of belonging to the Arabic and the English-speaking communities. The notion of belonging plays an important role in assessing the ethnolinguistic vitality of Arabic as it investigates the potentially fluid identities the participants have constructed, merging and moving between both English and Arabic. Bhabha (1983) argues that "fixity, as the sign of cultural/historical/racial difference in the discourse of colonialism, is a paradoxical mode of representation" (p. 18). This is because it infers a level of rigidity and an unchanging order within the subject's identity. Bhabha's argument is especially relevant in the context of the modern multicultural Australia, given the great diversity within the country's citizenry.

The results also highlight the lack of fixed identity amongst participants, indicating that they believed they could develop a sense of belonging across both ethnolinguistic communities. The majority of participants $(52 \%)$ said they felt they "very much" belonged to the Arabic speaking community. When asked how much they would like to associate with the community in the future, the numbers stayed relatively stable, only decreasing by $3 \%$ (down to $49 \%$ ). Conversely, $34 \%$ of participants said they "very much" felt that they belonged to the English-speaking community. Unlike the response to the Arabic based question, when asked "how much would you like to associate yourself with the English-speaking community in the future?", the number of participants who responded "very much" almost doubled (to 64\%). These results can be interpreted in two distinct ways, neither of which is exclusive of the other. Firstly, we can read the results as conveying the participants' desire to maintain their plurilingual, hybrid identities, in speaking both Arabic and English in the future. The results about belonging to the Arabic speaking community hardly shift, showing that participants don't want to limit their connection to Arabic. However, in showing an increased desire to associate with the English-speaking community, the participants' reveal their hope for a more pluralistic Australia, where the concept of "being" Australian is not limited by the languages you speak.

\section{Conclusion}

The investigation into the ethnolinguistic vitality of Arabic has been framed within the complex and at times contradictory multiculturalism that exists in Australia. By contextualising the study in this way, a nuanced understanding of the ways in which the Arabic ethnolinguistic community perceived both itself, and the Anglo-Australian English-speaking community has been developed. Given that Arabic is spoken 
by over 320,000 Australians and is the third most spoken language in the country following English and Mandarin (ABS 2016), the importance of examining the vitality of the language was evident ${ }^{22}$.

The results of the Subjective Ethnolinguistic Vitality Survey (SEVQ) further challenged the success of Australia's multiculturalism, in that it showed a distinct difference between the vitality of the Arabic language and the English language in the Australian linguistic landscape. The results highlighted the discrepancy between the size and social activity of the community, and the amount of formal institutional support the language received. When specifically looking at language education, Arabic was seen by $25 \%$ of participants to be well represented. Comparatively, $87 \%$ of participants noted that English was well represented. Such results once again demonstrate Australia's issue with the monolingual mind set, and the lack of a truly pluralistic education curriculum that allows bilingual Australians to view their language skills as important recourse in growing the Australian nation both here and on the international stage.

The results pertaining to the social status variable showed that participants believed there to be a lack of respect held in Australian society for the Arabic language. Additionally, participants believed that the way in which Arabic is portrayed across Australian media platforms negatively affects people's perception of the language. However, these results reveal that Arabic remains a strong presence in the Australian linguistic landscape, with a high rate of vitality, despite its low social status and lack of formal institutional support.

\section{Limitations and recommendations}

The limitations that arose throughout the research process centred on the ability to generalise the results, as the SEVQs were only distributed to Arabic-speaking residents in Melbourne, Victoria who were aged between 18 and 23. Given that Sydney is home to the largest Arabic-speaking community in Australia the ethnolinguistic community in Sydney may view itself as having a different rate of vitality than the community based in Melbourne. Additionally, the sampling process could have produced more diverse participants, allowing for a cross-generational sample. It is recommended that in future studies into the ethnolinguistic vitality of Arabic, a sample of Anglo-Australian participants are included so as to provide more validity, as well as more complex comparative data. However, the results of this study, conducted with 53 participants from the same age demographic, still provides invaluable insight into the way the Arabic language is used, maintained and engaged with. In doing so, it has paved the way for further research into the vitality of Arabic in Australia, on a larger and national scale.

\section{References}

Abdel-Fattah, R. (2017). Islamophobia and Everyday Multiculturalism in Australia, Routledge. Retrieved from https://ebookcentral.proquest.com.

Abrams, J. R., Barker, V. \& Giles, H. (2009). An examination of the validity of the Subjective Vitality Questionnaire. Journal of Multilingual \& Multicultural Development, 30 (1), 59-72.

Ahmed, S. \& Matthes, J. (2016). Media representations of Muslims and Islam from 2000 to 2015: A meta-analysis. International Communication Gazette, 39 (3), 219-244.

Akbarzadeh, S. (2016). The Muslim Question in Australia: Islamophobia and Muslim Alienation. Journal of Muslim Minority Affairs, 36 (3), 323-333.

Ang, I. (2003). From White Australia to Fortress Australia: The Anxious Nation in the New Century. In L. Jayasuriya, D. Walker \& J. Gothard (Eds.), Legacies of White Australia (pp. 51-70). Crawley, Australia: University of Western Australia Press.

Asmar, C. (1992). The Arab Australian Experience. In M. Goot \& R. Tiffen (Eds.), Australia's Gulf War (pp. 57-81). Carlton: Melbourne University Press.

Australian Bureau of Statistics. (2017, June). Census reveals a fast changing, culturally diverse nation. Retrieved from http://www.abs.gov.au/ausstats.

Australian Bureau of Statistics. (2016). 2016 Census Quickstats. Retrieved from http://www.abs.gov.au/websitedbs/D3310114.nsf/Home/2016\%20QuickStats.

\footnotetext{
22 Especially when considering the unique position Arabic holds in the Australian public imagination, and media landscape. Here, we are referring to the fact that Arabic is closely connected to Islam, and as such is often associated with acts of terrorism and violence amidst the current wave of Islamophobia (see OnePath Network, 2018)
} 
Australian Bureau of Statistics. (2011). 2011 Census Quickstats. Retrieved from

http://quickstats.censusdata.abs.gov.au/census_services/getproduct/census/2011/quickstat/0.

Bhabha, H. (1983). The Other Question. Screen, 24 (6), 18-36.

Bourhis, R.V., Giles, H. \& Rosenthal, D. (1981). Notes on the construction of a 'subjective vitality questionnaire' for ethnolinguistic groups. Journal of Multilingual \& Multicultural Development, 2 (2), 145-155.

Clyne, M. (2008). The monolingual mindset as an impediment to the development of plurilingual potential in Australia. Sociolinguistic Studies, 2 (3), 347-365.

Clyne, M. (2005). Australia's Language Potential. Sydney: UNSW Press.

Clyne, M. (2011). Multilingualism, Multiculturalism and Integration. In M. Clyne \& J. Jupp (Eds.), Multiculturalism and Integration: A Harmonious relationship (pp. 53-72). Canberra: ANU Press.

Clyne, M. \& Kipp, S. (1999). Pluricentric languages in an immigrant context: Spanish, Arabic and Chinese. Berlin: Walter de Gruyter.

Colic-Peisker, V., Mikola, M. \& Dekker, K. (2016). A Multicultural Nation and its (Muslim) Other? Political Leadership and Media Reporting in the Wake of the "Sydney Siege".Journal of Intercultural Studies, 37 (4), $373-$ 389.

De Swaan, A. (2013). Words of the World: The Global Language System. Oxford: Polity Press.

Dunn, K. (2004). Islam in Sydney: Contesting the Discourse of Absence. Australian Geographer, 35, 333-353.

Ehala, M. (2010). Ethnolinguistic vitality and intergroup processes. Multilingua -Journal of Cross Cultural and Interlanguage Communication, 29, 203-221.

Ehala, M. (2010). Refining the notion of ethnolinguistic vitality. International Journal of Multilingualism, 7 (4), 363378.

Department of Education and Training. (2017). Victorian Languages Provision, Languages Unit, Learning and Teaching Branch Secondary Reform, Transitions and Priority Cohorts Division. Melbourne, Vic: Author. Retrieved from http://www.education.vic.gov.au/Documents/school/teachers/teachingresources/disci pline/languages/2016_Languages_provision_report.pdf.

Department of Education and Training. (2010). Victorian Languages Provision, Languages Unit, Learning and Teaching Branch Secondary Reform, Transitions and Priority Cohorts Division. Melbourne, Vic: Author. Retrieved from http://www.education.vic.gov.au/Documents/school/teachers/teachingresources/disci pline/languages/lotereport2010.pdf.

Fishman, J. (1964). Language maintenance and language shift as a field of inquiry: A definition of the field and suggestions for its further development. Linguistics, 2 (9), 32-70.

Giles, H. \& Johnson, P. (1987). Ethnolinguistic identity theory: A social psychological approach to language maintenance. International Journal of the Sociology of Language, 68, 69-99.

Giles, H., Bourhis, R. Y. \& Taylor, D. M. (1977). Towards a theory of language in ethnic group relations. In H. Giles (Ed.), Language, Ethnicity and Intergroup relations (pp. 307-348). London: Academic Press.

Gogonas, N. (2009). Language shift in second generation Albanian immigrants in Greece. Journal of Multilingual and Multicultural Development, 30 (2), 95-110.

Hage, G. (1998). White Nation: Fantasies of White Supremacy in a multicultural society. Armadale, NSW: Pluto Press.

Hage, G. (2002). Citizenship and Honourability: belonging to Australia today. In G. Hage (Ed.), Arab-Australians Today (pp. 1-16). Melbourne, Vic: Melbourne University Press.

Hess, K. \& Waller, L. (2015). Community journalism in Australia: a media power perspective. Community Journalism, 4 (1), 2-10.

Human Rights and Equal Opportunity Commission. (2003). Isma - Listen: National consultations on eliminating prejudice against Arab and Muslim Australians. Sydney: Author.

Hussein, S. \& Poynting, S. (2017). We're Not Multicultural, but .... Journal of Intercultural Studies, 38 (3), $333-348$.

Itaoui, R. \& Dunn, K. (2017). Media Representations of Racism and Spatial Mobility: Young Muslim (Un)belonging in a Post-Cronulla Riot Sutherland. Journal of Intercultural Studies, 38 (3), 315-332.

Kay, P. \& Kempton, W. (1984). What is the Sapir-Whorf Hypothesis? American Anthropologist, 86 (1), 65-79.

Landry, R. \& Allard, R. (1994). Ethnolinguistic Vitality: a viable construct. Journal of the Sociology of Language, 108, 5-13.

LoBianco, J. (2017). Policy Activity for Heritage Languages: Connections with Representation and Citizenship. In D. M. Brinton, O. Kagan and S. Bauckus (Eds.), Heritage Language Education: A New Field Emerging (pp. 53-70). New York, NY: Routledge.

LoBianco, J. (2010). The Struggle to Retain Diversity in Language Education. In A. J. Liddecoat \& A. Scarino (Eds.), Australian Education: Problems, Prospects and Future Directions (pp. 97-108). Newcastle-upon-Tyne: Cambridge Scholars Publishing. 
LoBianco, J. \& Slaughter, Y. (2009). Second Languages and Australian schooling. Camberwell, Vic: Australian Council for Educational Research. Retrieved from https://research.acer.edu.au/cgi/viewcontent.cgi?article=1007\&context=aer.

Noels, K., Kil, H. \& Fang, Y. (2014). Ethnolinguistic Orientation and Language Variation: Measuring and Archiving Ethnolinguistic Vitality, Attitudes and Identity. Language and Linguistic Compass, 8 (11), 618-628.

OnePath Network. (2018). Islam in the Media 2017. Australia: OnePath Network, Retrieved from https://gallery.mailchimp.com/a128c8cb7a84b3cbc8070e0e0/files/f6798530-d7a8-46da-b315b24d6e8e90e7/OPN__mediaProject_Report_MARCH.pdf?utm_source=Islam+in+the+Media.

Osuri, G. \& Banjeree, B. (2004). White Diasporas: Media Representations of September 11 and the Unbearable Whiteness of Being in Australia. Social Semiotics, 14 (2), 154-171.

Pauwels, A. (2016). Language Maintenance and Shift. Cambridge, UK: Cambridge University Press.

Piller, I. (2016). Linguistic Diversity and Social Justice: An Introduction to Applied Sociolinguistics. New York, N.Y: Oxford University Press.

Poynting, S., Noble, G., Tabar, P. \& Collins, J. (2004). Bin Laden in the suburbs: criminalising the Arab Other. Sydney: Sydney Institute of Criminology Series.

Said, E. (1997). Covering Islam: How the Media and the Experts Determine How We See the Rest of the World. London, UK: Random House.

Scarino, A. (2014). Situating the challenges in current languages education policy in Australia-unlearning monolingualism. International Journal of Multilingualism, 11 (3), 289-306.

Shaaban, K. \& Ghaith, G. (2002). University Students' perceptions of the ethnolinguistic vitality of Arabic, French and English in Lebanon. Journal of Sociolinguistics, 6 (4), 557-574.

Simons, G. F. \& Fennig, D. S. (2018). Ethnologue: Languages of the World, Twenty-first edition. Dallas, TX: SIL International. Online version: http://www.ethnologue.com.

Smolicz, J. (1987). National language policies in Australia and the Philippines: A comparative perspective. In A. H. Omar (Ed.), National language communication and multilingual societies (pp. 382-418). Kuala Lumpur: Dewan Bahasa dan Pustaka.

Yagmur, K. (2011). Does Ethnolinguistic Vitality Theory account for the actual vitality of ethnic groups? A critical evaluation. Journal of Multilingual and Multicultural Development, 32 (2), 111-120.

Yagmur, K. \& Ehala, M. (2011). Tradition and innovation in the Ethnolinguistic Vitality theory. Journal of Multilingual and Multicultural Development, 32 (2), 101-110. 